\title{
Dukungan Sosial Orang Tua Anak dengan Down Syndrome dalam Grup WhatsApp
}

\section{Social Support by Parents with Down Syndrome Children on Whatsapp Group}

\author{
Azzumar Adhitia Santika, Firstty Soraya Anugraheny \& Yasmin Alvina* \\ LSPR Communication \& Business Institute,Indonesia
}

Diterima: 08 April 2020; Disetujui: 01 Mei 2020; Dipublish: 01 Juli 2020

\begin{abstract}
Abstrak
Tujuan dari penelitian adalah mendeskripsikan pemaknaan grup WhatsApp Persatuan Orang Tua Anak dengan Down Syndrome (POTADS) sebagai wadah social support oleh orang tua anak Down Syndrome di Indonesia yang merupakan pemberi social support bagi anak mereka. Seperti yang diketahui, bahwa orang tua merupakan pemberi dukungan sosial yang utama bagi sang anak. Terkait dengan masalah yang dihadapi oleh anak dengan Sindrom Down dan orang tuanya, Persatuan Orang Tua Anak dengan Down Syndrome (POTADS), hadir sebagai wadah yang bertujuan memberi dukungan kepada orang tua anak dengan Sindrom Down di Indonesia agar mereka senantiasa kuat, salah satunya melalui grup WhatsApp yang terbuka bagi mereka. Penelitian ini menggunakan metode fenomenologi yang bertujuan untuk mengetahui bagaimana pengalaman sadar keempat informan, yaitu Ibu Leli, Ibu Ni Luh, Ibu Ernie, dan Ibu Nunung, dalam menggunakan grup WhatsApp POTADS, yang mana pengalaman sadar tersebut akan menciptakan pemaknaan terhadapnya. Wawancara mendalam pun dilakukan untuk mendapatkan data penelitian. Hasilnya grup ini dimaknai bermanfaat karena selain mampu mendapatkan dukungan informasi yang berguna bagi perawatan anak, mereka juga mendapatkan dukungan emosional yang berguna sebagai perisai guna menghadapi courtesy stigma. Ketidakhadiran komunikasi nonverbal membuat komunikasi tatap muka dianggap lebih nyaman dalam penerimaan dukungan sosial.

Kata kunci; Dukungan Sosial, Sindrom Down, Courtesy Stigma, WhatsApp
\end{abstract}

Abstract

The purpose of this research is to describe the meaning of the WhatsApp Group of Parents of Children with Down Syndrome (POTADS) as a forum for social support by parents of Down Syndrome children in Indonesia who provide social support for their children. As is known, that parents are the main providers of social support for the child. Related to the problems faced by children with Down Syndrome and their parents, the Parents Association of Children with Down Syndrome (POTADS), comes as a forum that aims to provide support to parents of children with Down Syndrome in Indonesia so that they are always strong, one of them through groups WhatsApp is open for them. This study uses a phenomenological method that aims to find out how the conscious experiences of the four informants, namely Ms. Leli, Ms. Ni Luh, Ms. Ernie, and Ms. Nunung, in using the WhatsApp POTADS group, which conscious experience will create meaning. In-depth interviews were also conducted to obtain research data. The results of this group are useful because in addition to being able to get information support that is useful for child care, they also get emotional support that is useful as a shield to face courtesy stigma. The absence of nonverbal communication makes face-to-face communication more comfortable in receiving social support.

Keywords; Social Support, Down Syndrome, Courtesy Stigma, WhatsApp

How to Cite: Santika, A.A., Anugraheny, F.S, \& Alvina, Y. (2020). Dukungan Sosial Orang Tua Anak dengan Down Syndrome dalam Grup WhatsApp. PERSPEKTIF, 9 (2): 329-337

\footnotetext{
*Corresponding author:

E-mail: azzumaradhitia@amail.com
}

ISSN 2085-0328 (Print) ISSN 2684-9305(Online) 


\section{PENDAHULUAN}

Sindroma Down/Down Syndrome adalah abnormalitas kromosom yang terjadi pada seseorang, di mana terdapatnya jumlah yang berlebih pada kromosom ke 21 (National Down Syndrome Society, 2012). Jumlah yang berlebih pada kromosom ke 21 tersebut menyebabkan jumlah total kromosom anak dengan Down Syndrome lebih banyak dibanding dengan anak lainnya. Normalnya, manusia memiliki 46 kromosom, namun dikarenakan kelebihan kromosom tersebut, anak dengan Down Syndrome memiliki 47 kromosom (Spurgeon, 2014). Terkait dengan kelebihan kromosom tersebut, hal itu berpengaruh terhadap perkembangan fisik, kognisi, juga motorik anak yang bersangkutan (Oliveira, Neto, \& Tudella, 2016).

Terkait dengan kekurangan dan perbedaan yang dimiliki oleh anak dengan Down Syndrome tersebut, umumnya orang tua merasa kecewa ketika mengetahui anak mereka didiagnosa merupakan anak dengan Down Syndrome (Roizen \& Patterson, 2003). Hal tersebut dikarenakan menerima diagnosa Down Syndrome dapat membuat orang yang bersangkutan maupun keluarganya mendapatkan pelabelan dari masyarakat (Hemmati \& Solemani, 2010). Pelabelan tersebut terkait dengan stigma mengenai keterbatasan yang dimiliki oleh anak dengan Down Syndrome.

Stigma sendiri adalah penilaian negatif dari masyarakat terhadap suatu hal (Hemmati \& Solemani, 2010). Stigma pun bisa berdampak kepada orang terdekat dari mereka yang terstigma. Persepsi negatif masyarakat terkait stigma yang dilabeli tersebut. Goffman dalam Smith \& Hipper (2010) mengatakan Courtesy Stigma menganggap orang terdekat dari orang yang memiliki pelabelan menjadi co-owner dari pelabelan yang orang terdekatnya tersebut sandang.

Lebih lanjut, Malli, Forrester-Jones, \& Murphy (2016) mengatakan bahwa keluarga orang yang terstigma, terutama ia yang merawat individu tersebut, cenderung menginternalisasi pandangan negatif dari masyarakat juga mengalami rasa bersalah atas kondisi yang menimpa keluarganya tersebut. Untuk itu, Goffman dalam Liu, Xu, Sun, \& Dumenci (2014) mengatakan bahwa mereka yang menerima Courtesy Stigma juga merasa takut, terisolasi secara sosial, malu, serta merasa stress. Hal ini pun dialami oleh orang tua anak dengan Down Syndrome.

Di Indonesia, diskriminasi terhadap anak dengan Down Syndrome masih ada. Dalam sebuah pemberitaan yang pernah dimuat oleh Tribun Jabar (2014), Reny, seorang ibu dari anak dengan Down Syndrome mengungkapkan sulitnya mencari sekolah yang mau menerima anaknya. Ia berkali-kali ditolak oleh sekolah reguler. Bahkan di sekolah inklusi yang harusnya bisa menerima anak berkebutuhan khusus juga masih sulit. Tidak hanya di bidang pendidikan, di bidang kesehatan pun Reny mengatakan hingga saat itu tidak ada satupun pihak asuransi yang mau menerima anak dengan Down Syndrome.

Beberapa informan di dalam penelitian ini pun mengaku pernah mendapatkan diskriminasi terkait kondisi anak mereka. Diskriminasi tersebut berupa mendapat tatapan kurang menyenangkan dari orang lain di transportasi umum, maupun menerima cemoohan dari orang lain. Hal tesebut membuat mereka sedih.

Yayasan POTADS (Persatuan Orang Tua Anak dengan Down Syndrome) hadir di Indonesia sebagai wadah berkumpulnya para orang tua anak dengan Down Syndrome di Indonesia. POTADS bertujuan agar orang tua anak dengan Down Syndrome agar selalu bersemangat untuk membantu tumbuh kembang anak spesialnya secara maksimal. Sehingga mereka mampu menjadi pribadi yang mandiri, bahkan bisa berprestasi sehingga dapat diterima masyarakat luas (POTADS, 2016).

Selain melakukan kegiatan offline seperti mengedukasi masyarakat mengenai Down Syndrome melalui berbagai kegiatan juga memberdayakan orang tua serta anak dengan Down Syndrome, POTADS juga menyediakan grup WhatsApp yang terbuka bagi seluruh orang tua anak dengan Down Syndrome di Indonesia. Kegiatan yang dilakukan oleh POTADS tersebut berkaitan dengan konsep social support. Social support adalah salah satu konsep dalam komunikasi kesehatan yang hadir sebagai terapi sosial melalui jaringan-jaringan komunikasi guna membantu seseorang (pasien) dalam menghadapi masalah, khususnya masalah kesehatan, yang sedang dihadapinya (Moss 
dalam Thompson, Dorsey, Miller \& Parrott, 2003).

Jika mengacu pada definisi social support yang dikemukakan oleh Moss dalam Thompson, Dorsey, Miller \& Parrott (2003) tersebut, maka pasien dalam konteks penelitian ini adalah anak dengan Down Syndrome di Indonesia. Sedangkan jaringan komunikasi yang memberikan social support kepada anak dengan Down Syndrome tersebut ialah orang tua mereka. Sehingga, Grup WhatsApp POTADS yang beranggotakan orang tua anak dengan Down Syndrome menjadi wadah social support bagi mereka yang menjadi wadah social support bagi anak dengan Down Syndrome di Indonesia. Pemberian dukungan kepada orang tua anak dengan Down Syndrome dirasa penting, sebab Hemmati \& Solemani (2010) menunjukan bahwa keluarga anak dengan Down Syndrome mengalami peningkatan stress yang lebih tinggi dibanding dengan keluarga anak berkebutuhan khusus lain. Ditambah, Courtesy Stigma membuat mereka juga mengalami kesedihan terkait kondisi sang anak. Padahal, mereka adalah pihak pemberi dukungan bagi anak dengan Down Syndrome.

Hal ini merupakan kebaruan yang ditawarkan oleh penelitian ini. Sebab, berdasarkan studi literatur yang peneliti lakukan, beberapa penelitian terkait social support lebih berfokus kepada pasien. Seperti penelitian Hudkins, Johnson, Melton \& Wingert (2014) yang mencoba mencari tahu bagaimana penggunaan sosial media bagi individu penderita diabetes, juga penelitian Dare \& Green (2011) yang mencoba mencari tahu bagaimana perempuan di usia pertengahan (45 - 55 tahun) dalam menggunakan teknologi komunikasi dan informasi untuk mencari dukungan sosial. Sedangkan dalam penelitian ini, fokus pemberian social supportnya kepada orang tua anak dengan Down Syndrome di Indonesia, yang merupakan wadah social support bagi pasien.

\section{METODE PENELITIAN}

Penelitian ini menggunakan metode fenomenologi. Fenomenologi adalah sebuah pendekatan yang mencoba menguak bagaimana pengalaman sadar yang dialami oleh individu terkait dengan suatu hal (Guest, Namey \& Mitchell, 2012). Pengalaman sadar yang ingin peneliti cari tahu dari subjek penelitian adalah bagaimana pengalaman sadar orang tua anak dengan Down Syndrome dalam menggunakan grup WhatsApp POTADS sebagai wadah social support bagi mereka.Penelitian ini dilaksanakan di Jakarta dan Cilegon.

Penelitian ini memiliki 4 orang informan yang memenuhi kriteria yang telah dituliskan. Keempat informan tersebut ialah Leli Sulastri, $\mathrm{Ni}$ Luh S. Handayani, Ernie, dan Nunung Hanurawati. Wawancara mendalam pun dilakukan kepada keempat orang informan tersebut sebagai sebagai teknik pengumpulan data penelitian. Wawancara mendalam tersebut dilakukan di Jakarta dan Cilegon.

Teknik analisis data pada penelitian ini menggunakan Teknik analisis data yang dikemukakan oleh Van Kaam dalam Moustakas (1994), yaitu:

Tahap horizonalizing, yaitu tahap di mana peneliti mencoba melengkapi data dari berbagai sumber dan sudut pandang lain yang didapat dari informan penelitian. Dalam penelitian ini, peneliti mencoba melengkapi data-data dengan mewawancarai beberapa informan. Peneliti juga melakukan kroscek atas pernyataan informan satu kepada informan lainnya.

Thematic portrayal, yaitu tahap pengumpulan horizon yang telah dikelompokkan ke dalam tema-tema yang sesuai, agar dapat digunakan ke seluruh subjek penelitian. Selanjutnya, setelah peneliti menemukan keunikan dari pengalaman (invariant constituent) yang dihasilkan dalam proses wawancara, peneliti kemudian membangun gambaran tema-tema berdasarkan pengalaman tersebut. Thematic portrayal dalam penelitian ini ada tiga, yaitu Pengalaman memiliki anak dengan Down Syndrome, pengalaman bergabung dengan grup WhatsApp POTADS, pemaknaan akan grup WhatsApp POTADS.

Individual Textural Description, membuat penjelasan dan deskripsi tekstual. Deskripsi tekstual dalam penelitian ini adalah pemaparan mengenai apa pengalaman sadar yang dialami oleh orang tua anak dengan Down Syndrome di Indonesia yang tergabung dalam grup WhatsApp POTADS terkait dengan penggunaan grup tersebut. Termasuk di dalamnya adalah ekspresi harfiah (kata per kata) dari catatan wawancara. Individual 
textual description merupakan transkrip berupa data.

Individual Structural Description, yaitu penulis memaparkan bagaimana pengalaman tersebut dialami oleh individu. Dalam tahap ini, Hasbiansyah (2008) mengatakan peneliti juga mencari makna yang mungkin berdasarkan refleksi peneliti sendiri, berupa opini, penilaian, perasaan, serta harapan subjek penelitian berdasarkan pengalaman yang dialaminya. Sehingga, peneliti akan memaparkan bagaimana pengalaman sadar mengenai penggunaan grup WhatsApp POTADS yang dirasakan oleh orang tua yang tergabung di dalamnya.

Composite description, yaitu menggabungkan deskripsi tekstual dan struktural. Dalam fase ini, peneliti menggabungkan penjelasan tekstual dan penjelasan struktural yang telah dibuat sebelumnya. Dari penggabungan tersebut, peneliti akan mendapatkan makna dari hasil penelitian, yang nantinya akan dianalisis menggunakan teori untuk menghasilkan hasil yang lebih valid.

\section{HASIL DAN PEMBAHASAN}

Berdasarkan hasil penelitian, seluruh informan merasa sedih ketika pertama kali menerima diagnosa dari dokter bahwa anak mereka merupakan anak dengan Down Syndrome. Beberapa informan pun pernah mendapatkan diskriminasi dari masyarakat terkait kondisi sang anak, dan hal itu juga membuat mereka merasa sedih. Hal tersebut disebabkan adanya Courtesy Stigma yang menimpa orang tua anak Down Syndrome. Courtesy Stigma sendiri berarti pemberian stigma kepada seseorang terkait dengan hubungannya dengan orang atau kelompok yang memiliki stigma tertentu (Liu, et.al.,, 2014). Beberapa penelitian pun telah menunjukan adanya diskriminasi serta pemberian stigma sosial kepada keluarga individu dengan Down Syndrome (Hemmati \& Solemani, 2010).

Padahal, orang tua memainkan peran yang penting dalam pembentukan motivasi pencapaian anak (Joshi, 2011). Untuk itu, mereka pun membutuhkan social support untuk mengatasi masalah yang ada, sebab social support yang diberikan kepada orang tua anak Down Syndrome berpengaruh secara langsung terhadap perkembangan sang anak
(Hooste \& Maes, 2003). Salah satu wadah social support yang menaungi mereka adalah grup WhatsApp POTADS.

Seiring berjalannya waktu atas pengalaman mereka berinteraksi dengan Grup WhatsApp POTADS, orang tua anak dengan Down Syndrome yang tergabung di dalamnya pun akan memiliki pemaknaan pribadinya terkait grup WhatsApp tersebut. Hal tersebut didukung oleh pernyataan Ajidarma (2016) bahwa pemaknaan berarti suatu tanggapan yang tercipta berdasarkan perjalanan waktu. Perjalanan waktu tersebut pun terekam dalam pengalaman sadar yang dialami oleh informan dalam penelitian ini.

Berdasarkan hasil penelitian, para informan memaknai grup WhatsApp POTADS dapat menjadi wadah bagi para orang tua anak dengan Down Syndrome di Indonesia untuk saling belajar, berbagi, juga menjalin relasi. Para orang tua merasa terbantu dengan keberadaan grup WhatsApp POTADS. Hal ini didukung oleh pernyataan Thomas (2006) bahwa dalam konteks komunikasi kesehatan, perkembangan teknologi dapat membantu orang mendapatkan informasi dengan lebih mudah, seperti halnya dapat terhubung dengan sumber informasi tanpa perlu terkendala jarak.

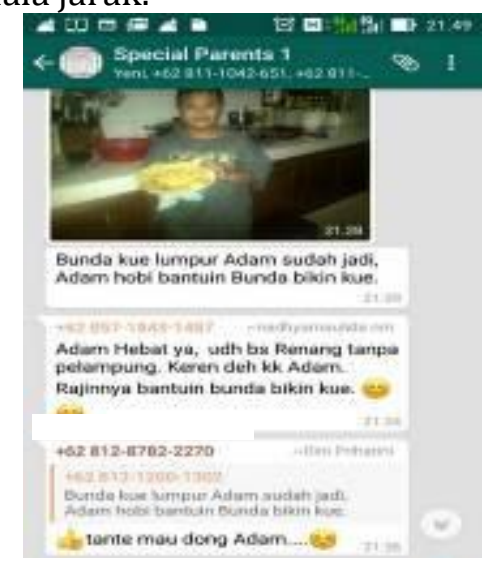

Gambar 1. Aktifitas di Grup WhatsApp POTADS

Sumber: Dokumentasi Peneliti (2017)

Selain dapat menjadi tempat belajar satu sama lain, di grup tersebut juga dapat menjadi tempat untuk mendapatkan dukungan dan relasi. Melalui ini mereka tidak perlu bertemu secara fisik, sehingga bisa dengan sangat mudah untuk memperoleh informasi. Sehingga bisa dikatakan bahwa grup ini dapat meningkatkan silaturahmi di antara orang tua anak dengan Down Syndrome yang lain. Sebagaimana yang dikatakan oleh Hopperton (2016;) bahwa Computer-Mediated 
Communication (CMC) atau komunikasi berbasis computer, bisa menjadi media pembelajaran bagi para anggotanya yang mencari dukungan informasi tanpa perlu khawatir terkendala ruang dan waktu.

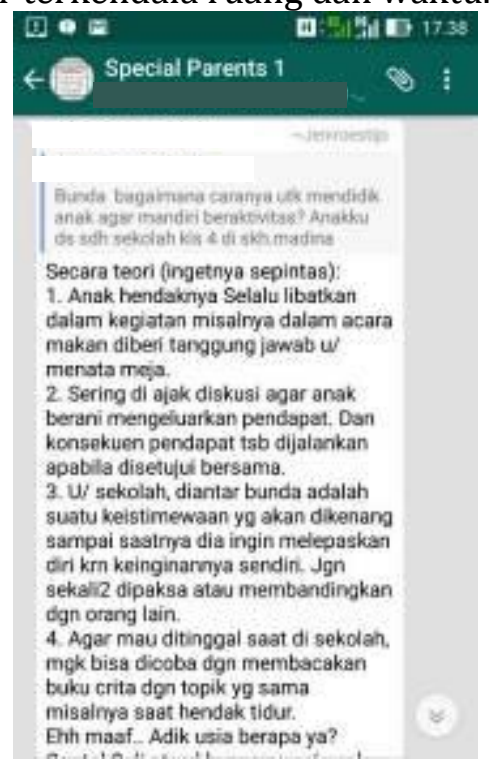

Gambar 2. Aktifitas di Grup WhatsApp POTADS (2017)

Sumber: Dokumentasi Peneliti (2017)

Berdasarkan hasil penelitian, ditemukan data bahwa grup WhatsApp POTADS juga menjalankan beberapa fungsi yang terdapat dalam konsep social support. Fungsi yang berjalan pada grup tersebut ialah emotional support, yaitu pemberian simpati kepada seseorang yang mana hal tersebut dapat meningkatkan self-esteem yang bersangkutan (Link, et.al., 2016). Penerimaan emotional support yang dialami oleh para informan adalah ketika mereka mengirimkan foto kegiatan anaknya, dan mendapatkan pujian juga dorongan semangat dalam komunikasi verbal dari anggota grup yang lain. Pujian serta semangat tersebut begitu berarti bagi mereka. Hal tersebut meningkatkan kepercayaan diri mereka.

Informational support diterima oleh para informan ketika mereka bertanya di grup perihal suatu hal, dan ada yang memberi jawaban. Seperti saat anak mereka sakit, atau saat mereka membutuhkan saran mengenai metode pembelajaran bagi anak, juga bertanya tentang informasi mengenai sekolah bagi sang anak. Mereka pun bertanya hal yang mereka tidak tahu, dan mendapatkan jawabannya dari mereka yang memiliki pengetahuan maupun pengalaman yang lebih.
Hanya ada 2 dukungan yang tersedia di dalam grup WhatsApp POTADS, yaitu emotional support dan informational support membuat praktik social support dalam grup WhatsApp POTADS tidak dapat menyuguhkan beberapa bentuk dukungan yang lain, seperti instrumental support dan companionship support. Cohen, Underwood, \& Gottlieb (2000, h. 88) mengemukakan kedua fungsi dukungan tersebut dapat didefinisikan sebagai:

Instrumental support, meliputi bantuan secara praktis yang dirasa dibutuhkan, seperti memberikan transportasi, membantu melakukan pekerjaan rumah serta menjaga anak, memberikan bantuan secara nyata seperti meminjamkan alat-alat maupun meminjamkan uang.

Companionship support yaitu ketersediaan seseorang untuk secara praktis terlibat di aktivitas individu yang sedang memiliki masalah tersebut, misalkan menemaninya melakukan aktivitas seharian.

Beberapa fungsi dukungan yang tidak dapat berjalan tersebut dikarenakan oleh keterbatasan dari grup WhatsApp POTADS. Grup WhatsApp POTADS yang berbasis daring, membuat hadirnya keterbatasan komunikasi nonverbal. Selain itu, jarak geografis para anggota yang saling berjauhan pun membuat pertemuan fisik tak bisa selalu terjadi setiap hari. Sedangkan instrumental support dan companionship support membutuhkan pertemuan fisik.

Terkait dengan jarak geografis, sebagai bentuk social support $C M C$, berdasarkan hasil penelitian ditemukan bahwa grup WhatsApp POTADS mampu mengatasi masalah geografis. Anggotanya tidak terbatas pada satu kota. Melainkan terhubung di seluruh Indonesia. Hal ini oleh Miller \& Gergen dalam Wright \& Bell (2003) dianggap sebagai suatu hal yang positif karena dapat memudahkan individu yang berjauhan untuk saling terhubung dan mendapat dukungan.

Hal tersebut benar adanya. Di dalam grup WhatsApp POTADS, anggota yang berada di luar Jakarta dan sekitarnya dikatakan memiliki aktivitas penggunaan grup yang lebih tinggi dibanding mereka yang berada di Jakarta dan sekitarnya. Hal tersebut dikarenakan mereka tidak memiliki akses fasilitas pun informasi sebanyak mereka yang berada di Jakarta. Sehingga mereka benarbenar menggunakan grup itu untuk 
mendapatkan dukungan yang mereka butuhkan.

Selain mereka yang berasal dari luar Jakarta dan sekitarnya, anggota yang aktif di grup tersebut juga didominasi oleh orang tua anak yang berusia masih kecil. Hal ini berdasarkan hasil penelitian disebabkan karena mereka tidak menemukan dukungan yang dapat menyelesaikan masalahnya dengan sumber daya yang ada di sekitar mereka, mereka pun akan mencari tempat yang dapat membantu mereka. Grup WhatsApp POTADS menjadi tempat di mana mereka bisa saling berdiskusi, meski tidak saling mengenal satu sama lain atau bisa dikatakan memiliki ikatan weak tie. Fenomena tersebut didukung oleh pernyataan Wright \& Bell (2003) yang menyatakan bahwa internet dapat menyediakan atau menyuguhkan weak tie support ketika closer ties tidak bisa membantu.

Kemampuannya menembus batas-batas geografi dan memberikan bantuan dari weak tie ketika closer tie tak dapat membantu rupanya bukan suatu hal yang sepenuhnya positif bagi salah seorang informan. Ia merasa grup barunya (setelah ia keluar dari grup WhatsApp POTADS) yang sebatas pada para orang tua anak dengan Down Syndrome di sekitar tempat tinggalnya memiliki rasa kekeluargaan yang jauh lebih erat dibanding grup WhatsApp POTADS, akibat kedekatan tempat tinggal dan ikatan sosial yang kuat karena sering terjadi perjumpaan.

Meski begitu, ketiga informan lainnya menganggap grup WhatsApp POTADS sudah cukup kekeluargaan karena adanya kesamaan nasib. Hal ini senada dengan pernyataan Wright (2000) bahwa kepuasan dalam kelompok daring ditentukan oleh besarnya sumber daya yang ada serta adanya homophily. Homophily dalam konteks penelitian ini adalah kesamaan nasib memiliki anak Down Syndrome.

Menurut Rains, et.al. (2016) menganggap keunikan dari social support melalui CMC ialah karena ia berbasis teks tidak seperti komunikasi tatap muka yang dapat berjumpa dengan lawan bicara secara langsung. Sedangkan sebagai bentuk $C M C$ pula, di dalam grup WhatsApp POTADS bentuk komunikasinya tidak hanya berbasis teks. Di sana mereka bisa mengirim foto maupun video. Meski tetap tanpa adanya tatap muka secara langsung yang memungkinkan bisa melihat ekspresi wajah, mendengar intonasi suara, juga saling menyentuh.

Terkait dengan hal itu, Walther \& Parks dalam Rains, et.al. (2016) mengatakan ketidakhadiran fisik dalam CMC menjadi faktor yang paling mendasar yang membedakan social support melalui CMC dengan social support yang didapat dari komunikasi tatap muka. Berdasarkan hal tersebut, maka di dalam social support melalui $C M C$, terdapat keterbatasan komunikasi nonverbal. Pandangan lain dari Colvin, et.al. (2004) mengatakan ketidakhadiran gesture tubuh malah membuat social support dirasa kurang lengkap.

Keterbatasan komunikasi nonverbal tersebut rupanya menimbulkan konflik di dalam grup WhatsApp POTADS. Bahasa tulisan membuat tidak ada jaminan bahwa makna yang dikonstruksi oleh si pengirim pesan akan diterima dengan sama seutuhnya oleh penerima pesan. Ketidaksamaan persepsi ini menimbulkan kesalahpahaman berupa tidak adanya pemahaman yang sama antara pengirim dengan penerima pesan, seperti ketika ada anggota yang mengirim pesan dengan huruf besar semua, hal tersebut bisa ditangkap oleh anggota yang lain bahwa si pengirim pesan sedang marah. Padahal belum tentu seperti itu. Perihal fenomena ini, Rains, et.al. (2016) memberikan dukungan dengan mengemukakan bahwa tidak dapat mendengar intonasi suara juga ekspresi wajah pemberi social support di CMC akibat ketidakhadiran fisik tersebut, menimbulkan kemungkinan terjadinya kesalahpahaman, dan berakibat pada bagaimana si penerima pesan memperepsikan pesan tersebut.

Keterbatasan komunikasi nonverbal juga membuat para informan lebih nyaman dengan praktik social support yang terjalin melalui komunikasi tatap muka. Di dalam komunikasi tatap muka, para informan merasa nyaman dan merasakan dukungan yang benar-benar nyata. Hal tersebut dikarenakan para informan dapat melihat langsung anak satu sama lain, dapat saling menyentuh, dapat mendengar intonasi suara juga dapat melihat ekspresi wajah. Sedangkan melalui grup WhatsApp hal tersebut tidak dapat dijumpai. Perasaan lebih nyaman ketika menerima dukungan di dalam komunikasi tatap muka tersebut tercipta kerena menurut 
Rains, et.al. (2016), tanpa kehadiran fisik serta komunikasi nonverbal di CMC, partisipan mengalami ketidakpastian yang lebih tinggi dibanding dengan ketika ia menerima pesanpesan suportif melalui komunikasi tatap muka. Secara frontal, Colvin, et.al. (2004) mengatakan CMC dirasa telah mengurangi hubungan relasi secara visual maupun audio secara langsung, di mana antara komunikator dan komunikan tak bisa saling melihat komunikasi nonverbal di dalam proses komunikasi yang sedang berlangsung.

Bertemu langsung dengan orang yang memberi dukungan secara langsung membuat informan dalam penelitian ini mampu menlai kredibilatas si pemberi dukungan secara nyata, seperti apakah dia tulus atau tidak. Namun, meski lebih menyukai praktik social support yang terjadi melalui komunikasi tatap muka, bukan berarti mereka menafikan dukungan-dukungan yang diperolehnya melalui grup WhatsApp. Mereka merasa terbantu dengan dukungan yang diperoleh melalui grup WhatsApp POTADS, kemudian dukungan tersebut pun semakin nyata dan terasa ketika terjadi pertemuan tatap muka. Sehingga, pertemuan tatap muka memperteguh dukungan yang diberikan oleh grup WhatsApp POTADS.

Temuan lain dalam penelitian ini ialah bahwa kekurangan social support dalam $C M C$ tidak hanya terdapat pada ketidakhadiran fisik yang menyebabkan terbatasnya komunikasi non-verbal. Melainkan disebabkan juga oleh adanya anggota yang sensitif, sehingga lebih mudah menyulut api konflik. Ada juga anggota yang terlalu mendominasi, sehingga dukungan pun oleh salah seorang informan dirasa kurang merata.

Terkait dengan adanya anggota yang terlalu mendominasi membuat salah seorang informan merasa dukungan yang ia dapat dari grup WhatsApp POTADS kurang. Hal tersebut dikarenakan ketika ia memposting sesuatu di grup WhatsApp POTADS, tidak banyak anggota yang menanggapi postingannya. Pada akhirnya pengalaman itu pun membuatnya sedih dan memutuskan untuk keluar dari grup, dan bergabung dengan grup yang lain. Namun, meski begitu ia tetap memandang positif grup WhatsApp POTADS dan berharap agar grup ini tetap ada, karena menjadi wadah bagi orang tua anak dengan Down Syndrome dalam lingkup yang luas.
Rasa sedih tersebut disebabkan karena adanya pengaruh antara penerimaan social support dengan kondisi mental dan psikis individu (Wright \& Bell, 2003). Hubungan tersebut ialah, penerimaan social support yang baik mampu menjadi perisai dari kemungkinan terjadinya depresi (Dean $\mathrm{d} \&$ Lin dalam Wright \& Bell, 2003). Sehingga, penerimaan social support yang kurang baik akan mempengaruhi kondisi psikis individu yang bersangkutan menjadi kurang baik pula. Termasuk munculnya rasa sedih yang dirasakan olehnya.

Lebih jauh lagi, kurangnya penerimaan social support pun berhubungan dengan kesepian. Hal tersebut ditunjukan oleh hasil penelitian Segrin \& Passalacqua (2010) yang menunjukan bahwa rendahnya penerimaan social support akan memunculkan rasa sepi. Dalam penelitian ini, rasa sepi akibat merasa kurang mendapat social support di dalam grup WhatsApp POTADS membuat individu merasa dicampakkan dan terisolir.

Ia pun pada akhirnya keluar dari grup WhatsApp POTADS dan bergabung dengan grup baru khusus orang tua anak dengan Down Syndrome di sekitar rumahnya. Ia merasa lebih nyaman berada di grup itu karena merasa lebih mendapat dukungan. Berdasarkan hal itu, dapat disimpulkan bahwa grup dengan skala yang kecil memungkinkan terciptanya pemerataan dukungan dengan lebih baik.

\section{SIMPULAN}

Grup WhatsApp POTADS oleh para anggotanya dimaknai di sana mereka dapat mengakses informasi yang sebelumnya belum pernah mereka ketahui. Hal ini meningkatkan pengetahuan mereka akan dunia Down Syndrome. Melalui grup WhatsApp POTADS, para informan juga mendapatkan dukungan emosional berupa pemberian semangat dan pujian. Dukungan emosional tersebut oleh para informan dirasa mampu meningkatkan semangat serta kepercayaan dirinya. Berdasarkan hasil penelitian, dukungandukungan yang diperoleh tersebut berguna untuk diterapkan dalam proses mendidik sang anak, seperti orang tua memiliki kiat-kiat baru ataupun merasa lebih semangat dalam mendidik si buah hati. Pemaknaan akan grup WhatsApp POTADS tersebut tercipta berdasarkan tanggapan mereka mengenai 
pengalaman sadarnya dalam bergabung dan menggunakan grup WhatsApp tersebut.

Informan merasa praktik social support yang ada di grup WhatsApp POTADS sudah dapat membantu mereka dalam mendapatkan informasi juga dukungan secara emosional. Kemudian, dukungan-dukungan tersebut akan lebih terasa ketika informan melakukan pertemuan langsung. Sehingga, pertemuan langsung tersebut meneguhkan dukungandukungan yang sebelumnya sudah diperoleh melalui grup WhatsApp POTADS. Hal tersebut dikarenakan di dalam komunikasi tatap muka, mereka dapat merasakan komunikasi nonverbal berupa dapat melihat ekspresi wajah, mendengar intonasi suara, juga melakukan sentuhan-sentuhan. Hal tersebut oleh para informan dirasa mampu membuat dukungan semakin terasa nyata, begitu pula dengan ketulusan yang semakin terlihat.

Konflik di dalam social support berbasis CMC tidak hanya disebabkan oleh keterbatasan komunikasi nonverbal, namun juga disebabkan oleh beberapa faktor seperti anggota yang terlalu banyak hingga menyebabkan terjadinya chat yang tidak tertanggapi karena tertumpuk oleh obrolan lainnya, juga faktor personal anggota yang mudah sensitif, kurang bisa menerima masukan, serta terlalu mendominasi di dalam grup.

Anggota yang berada di luar Jakarta dan sekitarnya serta mereka yang memiliki anak Down Syndrome yang lebih kecil cenderung lebih aktif di grup karena lebih membutuhkan dukungan.

\section{UCAPAN TERIMAKASIH}

Peneliti berterimakasih kepada seluruh pihak yang telah berkontribusi di dalam penelitian ini yakni Ibu Leli Sulastri, Ibu Ni Luh S. Handayani, Ibu Ernie, Ibu Nunung Hanurawati, dan Yayasan POTADS.

\section{DAFTAR PUSTAKA}

Cohen, S., Underwood, L. G., Gottlieb, B. H. (2000). Social support measurement and intervention: A guide for health and social scientists. New York: Oxford University Press.

Colvin, J., Chenoweth, L., Bold, M., \& Harding, M. (2004). Cargivers of older adults: Advantages and disadvantages of internet- based social support. Family Relation, 53 (1), $49-57$.

Dare, J., \& Green, L. (2011). Rethinking social support in women's midlife years: Women's experiences of social support in online environments. European Journal of Cultural Studies, 14(5) 473-490.

Guest, G., Namey, E., Mitchell, M. (2012). Collecting qualitative data: A field manual for applied research. London, Thousand Oaks, New Delhi and Singapore: SAGE Publications

Hemmati, S. Solemani, F. Seyednour, R. Dadkhah, A. (2010). Stigma in iranian Down Syndrome. Iranian Rehabilitation Journal, 8 (11), 13 18.

Hooste, A.V., \& Maes, B. (2003). Family factors in the early development of children with Down Syndrome. Journal of Early Intervension, 25 (4), 296 - 309.

Hopperton, L. (2016). Computer-mediated communication. In S. Danver (Ed.), The SAGE encyclopedia of online education (Vol. 3, pp. 235-238). Thousand Oaks, CA: SAGE Publications Ltd. doi: 10.4135/9781483318332.n80

Hudkins, E. S., Johnson, N., Melton, S., \& Wingert, A. (2014). Social media use among individuals with diabetes. The International Journal of Communication and Health, (4), 38 - 43.

Link, E., Baumann, E., \& Fruh, H. (2016). Online discourses about pregnancy: Privacy as a 'price' for supportive communication. The International Journal of Communication and Health, 8, 54-64.

Liu, H., Xu, Y., Sun, Y.,\& Dumenci, L. (2014). Measuring HIV stigma at the family level: Psychometric assessment of the chinese Courtesy Stigma scales (CCSSs). PLoS ONE 9(3): e92855. doi:10.1371/journal.pone.0092855

Malli, M.A., Forrester-Jones, R., Murphy, G. (2016). Stigma in youth with tourette's syndrome; a systematic review and synthesis. Eur Child Adolesc Psychiatry, (25), 127-139.

Moustakas, C. (1994). Phenomenological research methods. California: SAGE Publications.

National Down Syndrome Society. (2012). What is Down Syndrome? Diakses pada 15 Desember 2016, dari http://www.ndss.org/DownSyndrome/What-Is-Down-Syndrome/.

Oliveira, C. C., Neto, J. L. C., \& Tudella, E. (2016). Manual dexterity of children and adolescents with Down Syndrome: Systematic review of the literature. Journal of Genetic Syndromes \& Gene Therapy, 7 (4), 1 - 7 . 
POTADS. (2016). Tentang POTADS, diakses pada 15 Desember 2016 dari http://potads.or.id/about/.

Rains, S. A., Brunner, S. R., Akers, C., Pavlich, C. A., \& Goktas, S. (2016). Computer-mediated communication (CMC) and social support: Testing the effects of using CMC on support outcomes. Journal of Social and Personal Relationships, 1-20.

Roizen, N. J. Patterson, D. (2003). Downs syndrome. The Lancet, 361, 1281 - 1289.

Segrin, C., \& Passalacqua, S. A. (2010). Functions of loneliness, social support, health behaviors, and stress in association with poor Journal of Health Psychology, 8(1), 39-54.health. Health Communication, 25 (4), 312-322.

Smith, R. A. \& Hipper, T. J. (2010). Label management: Investigating how confidants encourage the use of communication strategies to avoid stigmatization. Health Communication, 25, h. 410-422.

Spurgeon, C.B. (2014). Physical activity in individuals with Down Syndrome. Thesis. University of Tennessee Honors Projects. http://trace.tennessee.edu/utk_chanhonopr oj/1718

Thomas, R. K. (2006). Health communication. New York: Springer.

Thompson, T. L., Dorsey, A., Miller, K. I., \& Parrott, R. (2003). Handbook of health communication. New Jersey: Lawrence Erlbaum Associates.

Wright \& Bell. (2003). Health-related support groups on the internet: Linking empirical findings to social support and computermediated communication theory 